UNIVERSITA
DEGLISTUDI
DI TORINO

\title{
LIFE-CYCLE WELFARE LOSSES FROM RULES-OF-THUMB ASSET ALLOCATION
}

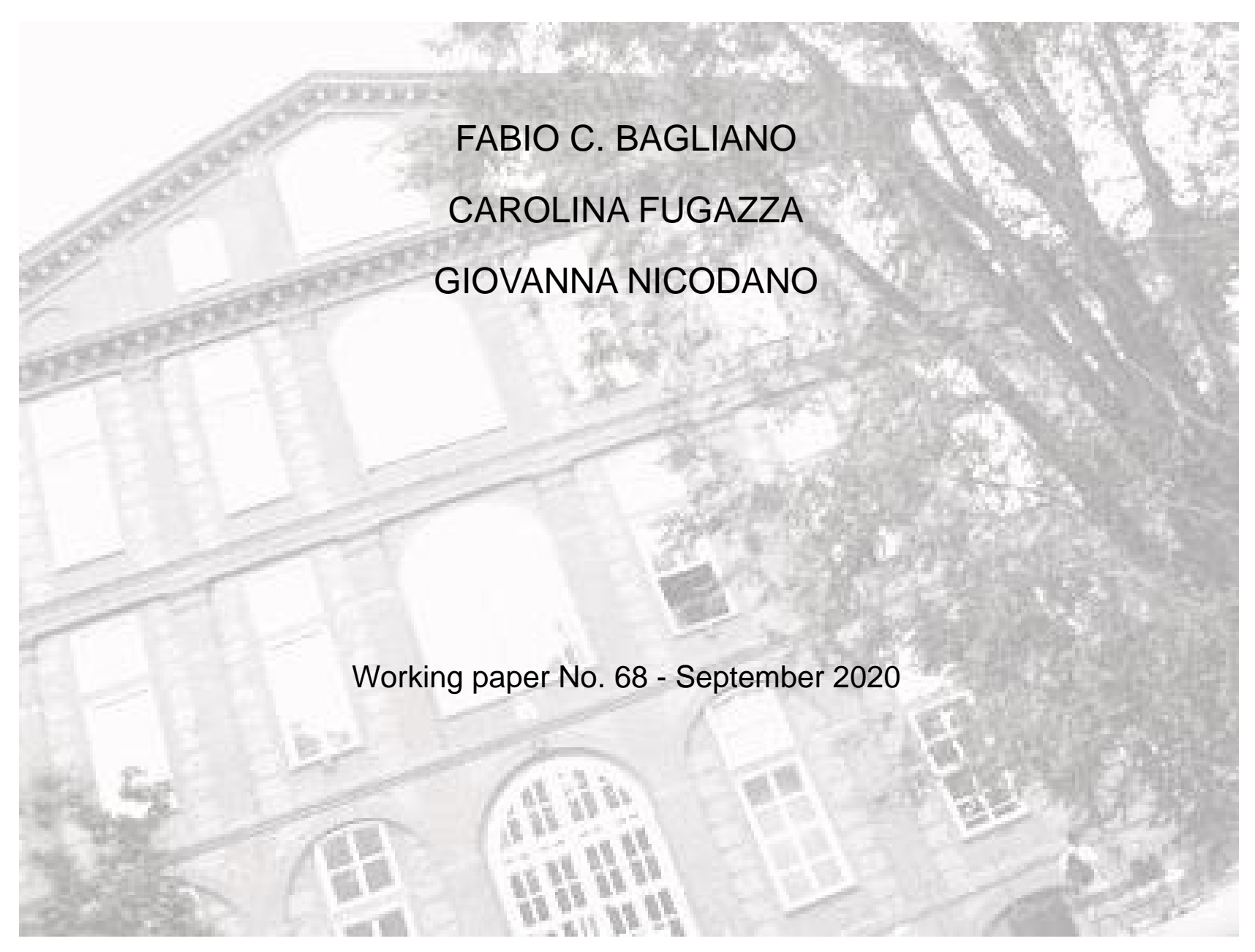




\title{
Life-Cycle Welfare Losses from Rules-of-Thumb Asset Allocation*
}

\author{
Fabio C. Bagliano^ Carolina Fugazza^ \\ Giovanna Nicodano^^

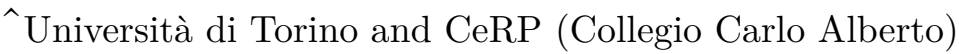 \\ ^^Università di Torino, CeRP (Collegio Carlo Alberto) and Netspar
}

August 2020

\begin{abstract}
How should workers invest over the life-cycle? Should they follow some typical prescriptions ("rules of thumb") in personal finance implying higher equity investments when young? We show that the answer hinges on the risk of long-term unemployment spells, entailing permanent declines in workers' future earnings prospects. Absent unemployment risk, extant prescriptions deliver portfolios that are close to optimal, implying negligible welfare losses. They instead lead to sizable welfare losses (3-9\% of annual consumption) when the risk of human capital depreciation following longterm unemployment is considered and realistically calibrated to the U.S. labor market. These losses stem from excess risk taking when young investors face uncertainty about future labor and pension incomes. This result points to a new design for pension plans offered by long-term institutional investors.
\end{abstract}

Keywords: welfare, life-cycle portfolio choice, unemployment risk, long term unemployment, age rules.

JEL classification: D15, E21, G11

Corresponding author: Fabio C. Bagliano, Dipartimento ESOMAS, Università di Torino, Corso Unione Sovietica 218bis, 10134, Torino (Italy); fabio.bagliano@unito.it

*We thank Antoine Bommier, Marie Brière, Bernard Dumas, Francisco Gomes, Luigi Guiso, Michael Haliassos, Tullio Jappelli, Dirk Krueger, Claus Munk, and Marco Pagano for useful comments and suggestions. We acknowledge financial support from the Italian MIUR ("Department of Excellence" 2018-2022 grant). 


\section{Introduction}

Workers usually delegate the task of managing their savings to pension funds and other long-term institutional investors. The latter often propose plans with a decreasing age profile of investment in the riskier assets, the equity share being often in excess of $80 \%$ when young. This practice approximates well the optimal asset allocation age profile obtained from standard life-cycle models of household portfolio choice (Cocco, Gomes and Maenhout, 2005; Gomes and Michaelides, 2005; Gomes, Kotlikoff and Viceira, 2008). In fact, the welfare loss incurred by agents who adopt popular investment "rules of thumb" instead of the optimal strategy is negligible, being equivalent to $0.2-0.8 \%$ of annual consumption. Importantly, those models do not allow for (possibly long-lasting) unemployment spells in the investor's working career.

This paper provides an assessment of the welfare loss associated with the use of simple investment rules when workers face long-term unemployment risk, yielding permanent reductions of their earning prospects. Such depreciation of workers' human capital as a consequence of prolonged unemployment has been recently documented by, among others, Edin and Gustavsson (2008) and Schmieder, von Wachter and Bender (2016); moreover, Kroft, Lange, Notowidigdo and Katz (2016) show that this phenomenon is common to all education groups and most industries in the U.S. in the aftermath of the Great Recession episode. Following this lead, a recent strand of literature in household finance extends the basic life-cycle setup to the possibility that investors experience periods of (even long-term) unemployment (Bremus and Kuzin 2014; Chang, Hong and Karabarbounis 2018; Bagliano, Fugazza and Nicodano 2019). However, none of those papers evaluate the welfare losses that investors incur should they not adopt the optimal portfolio allocation, following instead simpler rules of thumb.

The purpose of the present paper is to provide such welfare analysis, quantifying the loss due to the adoption of sub-optimal investment strategies in the presence of (realistically calibrated) long-term unemployment risk with permanent consequences on workers' human capital. We show that in this case the optimal age profile of stock investment is substantially different from the standard, decreasing with age, pattern: the equity share is lower for young workers and remarkably constant throughout working life and retirement. Consequently, the welfare loss associated with the adoption of simple rules of thumb is much larger (equivalent 
to $3 \%-9 \%$ of annual consumption), casting serious doubts on the appropriateness of popular financial advice on life-cycle asset allocation strategies.

The rest of the paper is organized as follows. In section 2, we describe a life-cycle model which accounts for long-term unemployment risk and calibrate it to match U.S. evidence. In section 3, we show and discuss the results on the optimal life-cycle profile of stock investment. Section 4 presents the welfare comparison of the optimal strategy with two very common suboptimal investment rules of thumb. Section 5 concludes.

\section{A life-cycle model with long-term unemployment risk}

We extend the standard model of life-cycle saving and portfolio allocation to allow for the possibility of long-term unemployment spells, entailing a deterioration of workers' human capital and therefore a permanent reduction of earning prospects.

\subsection{The model}

The investor maximizes the expected discounted utility of consumption over working life, starting at age $t_{0}$, and retirement, which begins with certainty at age $t_{0}+K$; she also wishes to leave a bequest. Life lasts at most $T$ periods, and is governed by age-dependent life expectancy: at each date $t$, the survival probability of being alive at date $t+1$ is $p_{t}$ (with $\left.p_{t_{0}-1}=1\right)$. Individual preferences are described by a time-separable power utility function:

$$
U_{t_{0}}=E_{t_{0}}\left[\frac{C_{t_{0}}^{1-\gamma}}{1-\gamma}+\sum_{j=1}^{T} \beta^{j}\left(\prod_{k=-1}^{j-2} p_{t_{0}+k}\right)\left(p_{t_{0}+j-1} \frac{C_{t_{0}+j}^{1-\gamma}}{1-\gamma}+\left(1-p_{t_{0}+j-1}\right) b \frac{\left(X_{t_{0}+j} / b\right)^{1-\gamma}}{1-\gamma}\right)\right]
$$

where $C_{t}$ is consumption at time $t, X_{t}$ is the amount of wealth (cash on hand) the investor leaves as a bequest if death occurs, $b \geq 0$ is a parameter capturing the strength of the bequest motive, $\beta<1$ is a utility discount factor, and $\gamma$ is the constant relative risk aversion parameter.

During working life individuals supply labor inelastically and receive exogenous stochastic earnings. To allow for long-term unemployment risk, we model working careers as a Markov chain with three possible states: employment $(e)$, short-term unemployment $\left(u_{1}\right)$ 
and long-term unemployment $\left(u_{2}\right)$, with the following transition matrix:

$$
\Pi_{s_{t}, s_{t+1}}=\left(\begin{array}{ccc}
\pi_{e e} & \pi_{e u_{1}} & \pi_{e u_{2}} \\
\pi_{u_{1} e} & \pi_{u_{1} u_{1}} & \pi_{u_{1} u_{2}} \\
\pi_{u_{2} e} & \pi_{u_{2} u_{1}} & \pi_{u_{2} u_{2}}
\end{array}\right)=\left(\begin{array}{ccc}
\pi_{e e} & 1-\pi_{e e} & 0 \\
\pi_{u_{1} e} & 0 & 1-\pi_{u_{1} e} \\
\pi_{u_{2} e} & 0 & 1-\pi_{u_{2} e}
\end{array}\right)
$$

where $\pi_{n m}=\operatorname{Prob}\left(s_{t+1}=n \mid s_{t}=m\right)$ with $n, m=e, u_{1}, u_{2}$. A worker employed at $t\left(s_{t}=e\right)$ can continue her employment spell at $t+1\left(s_{t+1}=e\right)$ with probability $\pi_{e e}$, or can enter shortterm unemployment $\left(s_{t+1}=u_{1}\right)$ with probability $\pi_{e u_{1}}=1-\pi_{e e}$. If short-term unemployed at $t\left(s_{t}=u_{1}\right)$, she exits unemployment $\left(s_{t+1}=e\right)$ with probability $\pi_{u_{1} e}$ or becomes longterm unemployed $\left(s_{t+1}=u_{2}\right)$ with probability $\pi_{u_{1} u_{2}}=1-\pi_{u_{1} e}$. Finally, if the worker is long-term unemployed at $t\left(s_{t}=u_{2}\right)$, she is re-employed in the following period $\left(s_{t+1}=e\right)$ with probability $\pi_{u_{2} e}$ and remains unemployed with probability $\pi_{u_{2} u_{2}}=1-\pi_{u_{2} e}$.

In each period, an employed worker earns labor income $Y_{t}$ driven by permanent and transitory shocks, as in Cocco, Gomes and Maenhout (2005). $Y_{t}$ is generated by the following process:

$$
Y_{t}=H_{t} U_{t} \quad t_{0} \leq t \leq t_{0}+K
$$

where $H_{t}=F\left(t, \mathbf{Z}_{t}\right) P_{t}$ represents the permanent income component. In particular, $F\left(t, \mathbf{Z}_{t}\right)$ captures the deterministic trend in income that depends on age $(t)$ and a vector of individual characteristics $\left(\mathbf{Z}_{t}\right)$ such as gender, marital status, household composition and education. The logarithm of the stochastic permanent component $P_{t}$ is assumed to follow a random walk process:

$$
\log P_{t}=\log P_{t-1}+\omega_{t}
$$

where $\omega_{t}$ is distributed as $N\left(0, \sigma_{\omega}^{2}\right)$. Finally, $U_{t}$ denotes the transitory stochastic component and $\varepsilon_{t} \equiv \log \left(U_{t}\right)$ is distributed as $N\left(0, \sigma_{\varepsilon}^{2}\right)$ and uncorrelated with $\omega_{t}$.

We extend this standard specification of the income process by introducing the novelty that unemployment duration affects the permanent component of labor income: the longer the unemployment spell, the larger is the worker's human capital depreciation, causing a permanent decrease in expected future earnings. After one-period unemployment the permanent component of labor income $H_{t}$ is equal to $H_{t-1}$ eroded by a fraction $\Psi_{1}$, and after a two-period unemployment $H_{t}$ is reduced by a fraction $\Psi_{2}>\Psi_{1}$. Thus, permanent 
labor income evolves according to

$$
H_{t}=\left\{\begin{array}{ll}
F_{t} P_{t} & \text { if } s_{t}=e \text { and } s_{t-1}=e \\
\left(1-\Psi_{1}\right) H_{t-1} & \text { if } s_{t}=e \text { and } s_{t-1}=u_{1} \\
\left(1-\Psi_{2}\right) H_{t-1} & \text { if } s_{t}=e \text { and } s_{t-1}=u_{2}
\end{array} \quad t=t_{0}, \ldots, t_{0}+K\right.
$$

During unemployment, the worker receives unemployment benefits as a fixed proportion ( $\xi_{1}$ and $\xi_{2}$ in the case of short-term and long-term unemployment, respectively) of her last working year labor income. Finally, as in the standard life-cycle model, during retirement the individual receives income equal to a fraction $\lambda$ of the permanent labor income earned in her last working year.

During both working life and retirement, savings can be invested in a short-term riskless asset, yielding a constant gross real return $R^{f}$, and one risky asset ("stocks") yielding stochastic gross real returns $R_{t}^{s}$ in each period. The excess returns of stocks is modelled as $R_{t}^{s}-R^{f}=\mu^{s}+\nu_{t}^{s}$, where $\mu^{s}$ is the expected stock premium and $\nu_{t}^{s}$ is a normally distributed innovation, with mean zero and variance $\sigma_{s}^{2}$.

Given uncertain labor income and asset returns, the investor maximizes expected discounted utility over her life span by choosing optimal consumption and portfolio allocation rules. We formulate her problem recursively by means of the following Bellman equation:

$$
\begin{aligned}
V_{t}\left(X_{t}, P_{t}, s_{t}\right)=\max _{C_{t}, \alpha_{t}^{s}} \frac{C_{t}^{1-\gamma}}{1-\gamma}+\beta & {\left[p_{t} \sum_{s_{t+1}=e, u_{1}, u_{2}} \pi\left(s_{t+1} \mid s_{t}\right) \widetilde{E}_{t} V_{t+1}\left(X_{t+1}, P_{t+1}, s_{t+1}\right)\right.} \\
& \left.+\left(1-p_{t}\right) b \frac{\left(X_{t+1} / b\right)^{1-\gamma}}{1-\gamma}\right]
\end{aligned}
$$

subject to $X_{t+1}=\left(X_{t}-C_{t}\right)\left(\alpha_{t}^{s} R_{t}^{s}+\left(1-\alpha_{t}^{s}\right) R^{f}\right)+Y_{t+1}$, with $\alpha_{i t}^{s}$ and $\left(1-\alpha_{t}^{s}\right)$ denoting the shares of the investor's portfolio invested in stocks and in the riskless asset respectively. ${ }^{1}$ In $(6), \widetilde{E_{t}}$ denotes the expectation operator taken with respect to continuous stochastic variables $\left(\omega_{t+1}, \varepsilon_{t+1}\right.$ and $\left.\nu_{t+1}^{s}\right)$, and $\pi\left(s_{t+1} \mid s_{t}\right)$ are the entries of the transition matrix (2). We solve this problem, that does not admit a closed form solution, by means of numerical techniques. $^{2}$

\footnotetext{
${ }^{1}$ We do not allow for short sales and we assume that the investor is liquidity constrained. Consequently, the amounts invested in stocks and in the riskless asset are non negative in all periods.

${ }^{2}$ Details on the solution procedure are reported in the online Appendix A, where we also show how the evolution of the permanent component of labor income depends on previous individual labor market
} 


\subsection{Calibration}

Calibration of the model requires choosing parameters of the investor's preferences, labor and retirement incomes, and the moments of stock returns. In order to focus on the role of long-term unemployment risk in shaping optimal life-cycle portfolio allocation, we adopt, wherever possible, the calibration in Cocco, Gomes and Maenhout (2005), a standard benchmark in the literature. Table 1 collects the values of the key parameters of the model, calibrated to the U.S. economy, with source references. In what follows we comment on our main choices.

\section{Table 1: Calibration parameters}

\begin{tabular}{|c|c|c|c|}
\hline Description & Parameter & Value & Source \\
\hline Working life & & $20-65$ & Cocco et al. (2005) \\
\hline Retirement & & $65-100$ & Cocco et al. (2005) \\
\hline Risk aversion & $\gamma$ & 5 & Chang et al. (2018) \\
\hline Replacement ratio & $\lambda$ & 0.68 & OECD $(2015)$ \\
\hline Discount factor & $\beta$ & 0.96 & Cocco et al. (2005) \\
\hline Bequest Motive & $b$ & 2.5 & $\begin{array}{l}\text { Gomes and Michaelides } \\
(2005)\end{array}$ \\
\hline $\begin{array}{l}\text { Variance of permanent shocks to la- } \\
\text { bor income }\end{array}$ & $\sigma_{\omega}^{2}$ & 0.0106 & Cocco et al. (2005) \\
\hline $\begin{array}{l}\text { Variance of transitory shocks to la- } \\
\text { bor income }\end{array}$ & $\sigma_{\epsilon}^{2}$ & 0.0738 & Cocco et al. (2005) \\
\hline Riskless rate & $r$ & $2 \%$ & Cocco et al. (2005) \\
\hline Excess returns on stocks & $\mu^{s}$ & $4 \%$ & Cocco et al. (2005) \\
\hline Variance of stock returns innovations & $\sigma_{s}^{2}$ & 0.025 & Cocco et al. (2005) \\
\hline $\begin{array}{l}\text { Stock ret./permanent lab. income } \\
\text { shock correlation }\end{array}$ & $\rho_{S Y}$ & 0 & Cocco et al. (2015) \\
\hline \multicolumn{4}{|l|}{ Unemployment benefits } \\
\hline Short-term unemployed & $\xi_{1}$ & 0.3 & OECD (2010) \\
\hline Long-term unemployed & $\xi_{2}$ & 0.1 & OECD (2010) \\
\hline \multicolumn{4}{|l|}{ Human Capital Loss } \\
\hline Short-term unemployed & $\Psi_{1}$ & 0 & \\
\hline Long-term unemployed & $\Psi_{2}$ & 0.25 & Jacobson et al. (1993) \\
\hline
\end{tabular}

This table reports benchmark values of relevant parameters with source references.

The investor's working life spans (at most) 45 periods, from the age of 20 up to 65, when retirement occurs. After retirement, she can live for a maximum of 35 periods until the dynamics. 
age of $100 .^{3}$ As for preferences, we set the coefficient of relative risk aversion $\gamma=5$, as in Chang, Hong and Karabarbounis (2018), much lower than the value typically adopted in the literature. ${ }^{4}$ The riskless rate is fixed at $2 \%$ and the expected equity premium $\mu^{s}$ at $4 \%$, with stock returns innovations, uncorrelated with permanent labor income shocks, displaying a variance set at 0.025 . The labor income process is calibrated using the estimated parameters for U.S. households with high school education (but not a college degree) in Cocco, Gomes and Maenhout (2005). ${ }^{5}$ After retirement, income is a constant proportion $\lambda$ of the final (permanent) labor income, set at 0.68 , as the net replacement rate of total pension benefits for the average earner in the U.S. (OECD, 2015).

In our model workers bear the risk of (possibly persistent) unemployment. The annual transition probabilities among labor market states (employment, short-term unemployment and long-term unemployment) are chosen to match the average unemployment rate experienced by the U.S. in recent years. In particular, using data from the Current Population Survey (CPS) reported by Kroft, Lange, Notowidigdo and Katz (2016), we calibrate the annual transition probability from employment to (short-term) unemployment at $4 \%$ and the probability of leaving unemployment after the first year at $85 \%$. Finally, we set the probability of transition from long-term unemployment to employment at $33 \%$ in order to yield unconditional probabilities of being short-term and long-term unemployed matching our U.S. post-Great Recession target. The resulting annual transition matrix

$$
\Pi_{s_{t}, s_{t+1}}=\left(\begin{array}{ccc}
0.96 & 0.04 & 0 \\
0.85 & 0 & 0.15 \\
0.33 & 0 & 0.67
\end{array}\right)
$$

delivers unconditional probabilities of being short-run (3.8\%) and long-run unemployed $(1.7 \%)$ in line with the overall (5.5\%) and long-term $(1.7 \%)$ unemployment rates occurred in the U.S. in 2015.

\footnotetext{
${ }^{3}$ In each period, we take the conditional probability of being alive in the next period $p_{t}$ from the life expectancy tables of the U.S. National Center for Health Statistics

${ }^{4}$ Other preference parameters are the utility discount factor $\beta=0.96$ (as in Cocco, Gomes and Maenhout, 2005 ), and the parameter capturing the strength of the bequest motive $b=2.5$ (as in Gomes and Michaelides, 2005), which bears the interpretation of the number of years of her descendants' consumption that the investor intends to save for.

${ }^{5}$ For the high school group, the variances of the permanent and transitory shocks ( $\omega_{t}$ and $\varepsilon_{t}$ respectively) are equal to $\sigma_{\omega}^{2}=0.0106$ and $\sigma_{\varepsilon}^{2}=0.0738$. The age-dependent trend is captured by a third-order polynomial in age fitted to the age coefficients estimates in Cocco, Gomes and Maenhout (2005), delivering a typical hump-shaped profile until retirement.
} 
Moreover, long unemployment spells entail a loss in the worker's expected permanent earnings due to human capital depreciation as shown in (5). We base our calibration of the effects of protracted inactivity on job careers on the evidence provided by Jacobson, LaLonde and Sullivan (2005), who estimate that average earnings losses for displaced workers amount to $43-66 \%$ of their predisplacement wage, and by Guevenen, Karahn, Ozkan and Song (2017), who find that the median earnings loss after a full year nonemployment amounts to $50 \%$ of previous income. Other studies document smaller earning losses, varying from 15\% (Couch and Placzek, 2010) to about 25\% (Jacobson, LaLonde and Sullivan, 1993) of predisplacement levels. Given the wide range of estimates of earning losses, we make a rather conservative choice, setting $\Psi_{1}=0$ (no loss for short-term unemployed) and $\Psi_{2}=0.25$, implying a $25 \%$ reduction of the permanent labor income component from the second year of unemployment.

Finally, unemployment benefits are calibrated according to the U.S. unemployment insurance system (OECD, 2010). Considering that the replacement rate with respect to last labor income is on average low and state benefits are paid for a maximum of 26 weeks, we set $\xi_{1}=0.3$ in case of short-term unemployment spells and a smaller value of $\xi_{2}=0.1$ for the long-term unemployed.

\section{Results}

Solving the model with the parameters displayed in Table 1 yields optimal policy functions for consumption and the portfolio share invested in stocks. ${ }^{6}$ Using those functions we simulate the whole life-cycle consumption and portfolio allocation decisions of a very large number of individuals (200.000) who start working at age 20 and face the realizations of shocks to labor income and stock returns drawn from the stochastic processes with parameter values reported in Table 1. In each period, the evolution of workers' employment status is driven by the transition probabilities in (7).

Figure 1 shows selected percentiles (20th, 50th, and 80th) of the distribution of investors' optimal risky portfolio share along the life cycle. As a benchmark for comparison, the Figure also displays the corresponding life-cycle profiles obtained from solving and simulating the model without unemployment risk. The latter scenario is obtained by setting $\pi_{e e}=1$ and all other entries equal to 0 in (2) and corresponds to the standard life-cycle set-up in Cocco,

\footnotetext{
${ }^{6}$ Th policy functions for the risky portfolio share are shown and discussed in the online Appendix B.
} 
Gomes and Maenhout (2005).

\section{Figure 1: Optimal life-cycle stock share profiles}

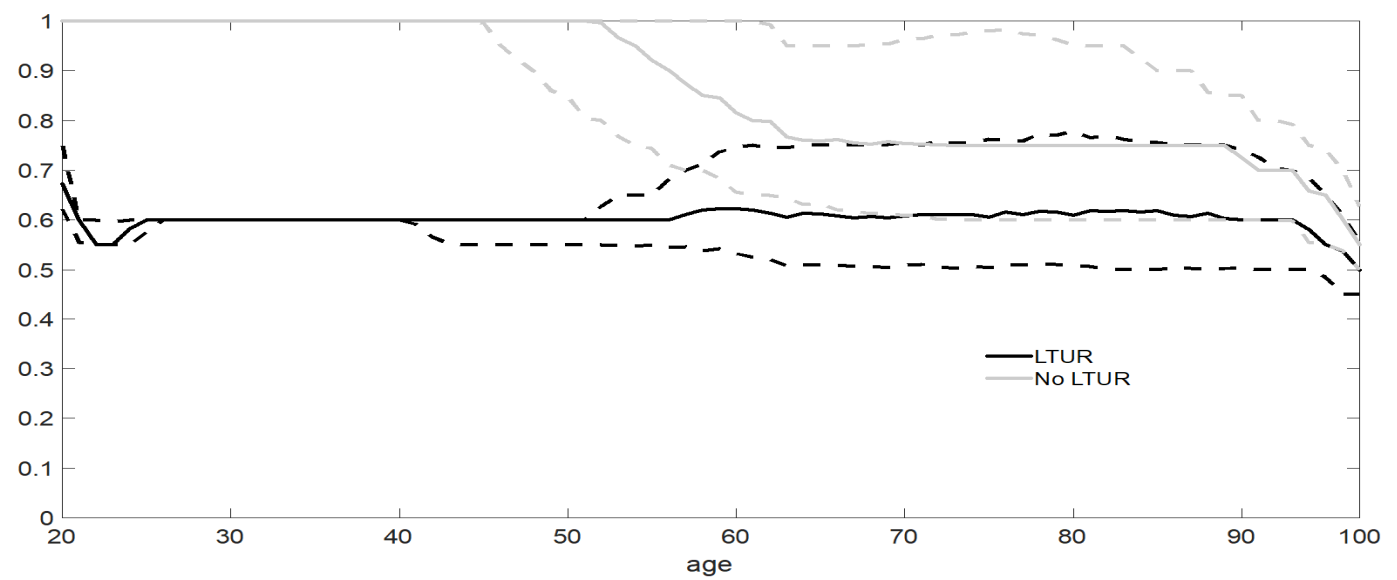

This figure displays the distribution of simulated stock investment life-cycle profiles for individuals of age 20 to 100 in the case of long-term unemployment risk (LTUR, black lines), and No long-term unemployment risk (No LTUR, grey lines). Medians are represented by solid lines, the $20 t h$ and the $80 t h$ percentiles by dashed lines.

In the case of no unemployment risk, the typical result on the age profile of the optimal stock portfolio share is obtained: the median investment in stocks is $100 \%$ during most of the working life and then decreases with age to reach around $75 \%$ at retirement and thereafter. The reason why investors should reduce exposure to risky assets as they approach retirement is that human capital provides a hedge against shocks to stock returns, making financial risk bearing more attractive. In early and middle stages of working life, when human capital is large relative to accumulated financial wealth, investment in stocks should be high; as retirement approaches human capital decreases relative to financial wealth and the portfolio should be rebalanced towards less risky assets.

When long-term unemployment risk is introduced, entailing rare but permanent declines in future earnings, the optimal stock share is sizably reduced at any age and almost flat at around $60 \%$, as Figure 1 shows. In this setting, human capital is lower and riskier, particularly for younger workers, inducing lower stock investment over the whole working life. Moreover, as workers grow older, two offsetting effects are at work. First, the standard hedge effect of the decrease in human capital over time causes a reduction in the optimal stock portfolio share. Second, as the worker safely comes close to retirement, the risk of long-term 
unemployment falls, thereby reducing the uncertainty on future labor (and pension) incomes. Overall, the resolution of uncertainty compensates the hedge effect, making the optimal risky portfolio share relatively flat over the life cycle. Therefore, introducing long-term unemployment risk with human capital loss not only reduces the level of stock investment, but also alters substantially its life-cycle profile, departing from the conventional wisdom pointing to a larger risky investment when young and a gradual shift to more conservative portfolios over time.

In addition to the median, Figure 1 displays the 20th and 80th percentiles of the distribution of the optimal stock share across individuals. The introduction of permanent consequences of long-term unemployment shrinks the heterogeneity of optimal portfolio choices across agents characterized by different employment histories. Along most of the working life, a large portion of the distribution is closely gathered around the median allocation, and the dispersion of optimal shares increases only near retirement and remains constant thereafter. The similarity of portfolio choices of a large number of investors is due to the shape of the optimal policy functions, that are relatively flat for a wide range of wealth levels, implying that even sizable differences in the amount of accumulated wealth result in homogeneous asset allocation choices. ${ }^{7}$

Overall, considering the risk of human capital losses due to the occurrence of (rare) long-term unemployment spells has important consequences for optimal life-cycle asset allocation: a lower portfolio share invested in risky assets (even with a moderate degree of risk aversion), with a remarkably flat age profile. This is in sharp contrast with the implications of the standard life-cycle model embodied in the popular financial advice of a high stock exposure when young, steadily decreasing with age. Our main results are robust to a wide range of changes in parameter calibration and extensions of the model. Bagliano, Fugazza and Nicodano (2019) show that the flat stock investment profile obtains also when the human capital loss due to long-term unemployment (captured by $\Psi_{2}$ ) is reduced from $25 \%$ to $15 \%$ of previous permanent labor incomes and the probability of entering long-term unemployment $\left(\pi_{u_{1} u_{2}}\right)$ is decreased from $15 \%$ to $10 \%$. The same conclusion applies when long-term unemployment risk is modelled as age-dependent, being lower for younger workers and increasing with age. Similarly, changes in the degree of risk aversion $(\gamma)$ affect only the average level but not the flat age profile of stock investment, which is also preserved

\footnotetext{
${ }^{7}$ Online Appendix B shows policy functions for the risky portfolio share at various ages.
} 
during the whole working life when the utility discount factor $(\beta)$ is substantially reduced from 0.96 to 0.85. In addition, Appendix $\mathrm{C}$ shows that adopting Epstein-Zin preferences (whereby the elasticity of intertemporal substitution can be set independently of the degree of risk aversion) and assuming a positive correlation between stock return and labor income innovations do not substantially alter the flatness of the risky share age profile, only reducing its level during working life in the latter case. Overall, the preceding experiments confirm the robustness of our results, pointing to the relevance of the human capital loss effect in shaping optimal life-cycle asset allocation choices.

\section{Welfare analysis}

The main features of optimal stock investment obtained from standard life-cycle models of asset allocation are embodied in simple investment rules proposed by pension funds and other institutional investors and in popular financial advice. Those rules broadly share the distinctive features of a large stock share for young workers (often in excess of 80\%), declining gradually to a more modest level when investors approach retirement. For example, Vanguard's long-run investment strategy is explicitly based on the results of standard lifecycle models: "The majority of younger individuals' ultimate retirement wealth is in the form of what they will earn in the future, or their human capital. Therefore, it may be appropriate for a younger person's portfolio to have a large committment to stocks to balance and diversify his or her risk exposure to work-related earnings (Viceira, 2001; Cocco, Gomes and Maenhout, 2005). ... [E]quity allocations should decline with age to help manage risk through time." (Vanguard, 2019, p. 3). The welfare loss associated with the adoption of simple "rules of thumb" instead of the optimal life-cycle profile is typically low and comparable to a lifetime reduction of the investor's annual consumption level in the range of $0.2-0.8 \%$ (Cocco, Gomes and Maenhout, 2005; Love, 2013). ${ }^{8}$

As shown in the previous section, when the possibility of long-term unemployment with human capital loss is allowed for, the resulting optimal age profile of stock investment is remarkably different: the risky portfolio share is lower on average during working life and relatively flat along the whole life cycle. This section provides a quantitative assessment of

\footnotetext{
${ }^{8}$ Larger welfare losses are obtained only when individuals can flexibly choose working hours and the age of retirement, and can invest in payout annuities beside stocks and bonds (Chai, Horneff, Maurer and Mitchell, 2011).
} 
the welfare loss incurred by agents who follow simple portfolio allocation rules related to age in this alternative environment. In particular, we compare the optimal asset allocation policy, displayed in Figure 2 as the solid line, with two suboptimal investment rules related to the investor's age.

\section{Figure 2: Optimal and suboptimal life-cycle stock share profiles}

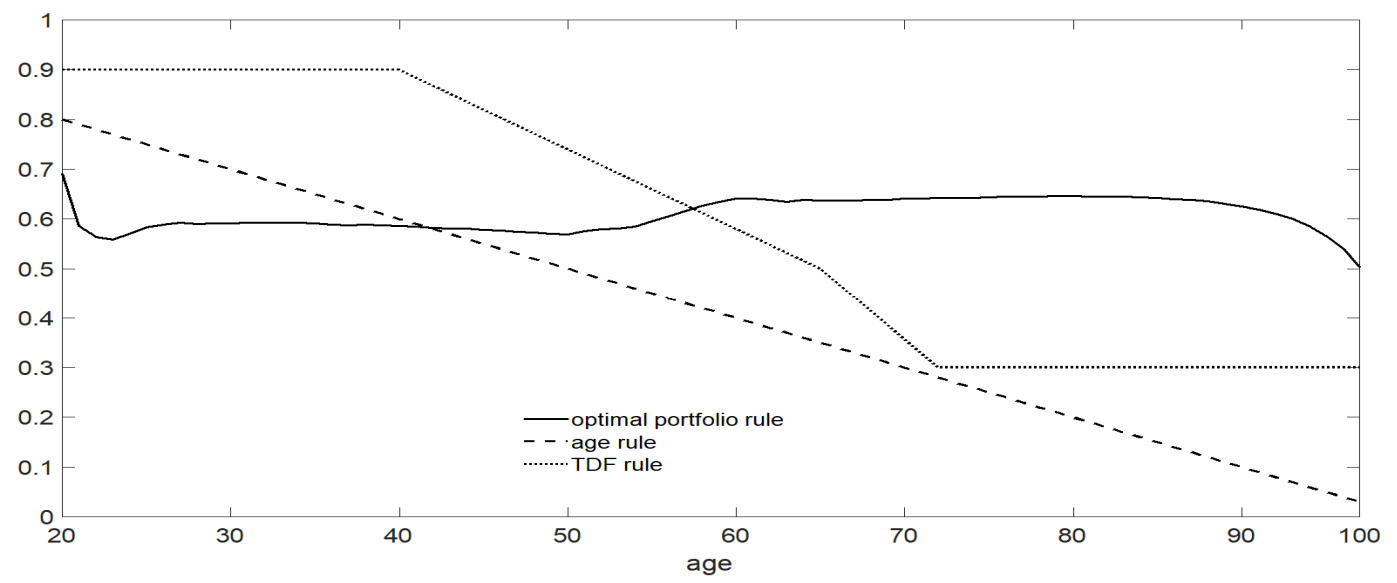

This figure displays the optimal (average of 200.000) life cycle profiles (solid line), and suboptimal life cycle profiles (dashed line) for portfolio choice: "age rule"; dotted line: "Target Date Fund rule").

The first is the typical "age rule", frequently suggested by financial advisors, whereby the risky portfolio share is set at 100 less the investor's age. This age rule is depicted in Figure 2 as the dashed straight line. The second rule of thumb is representative of the actual strategic asset allocation patterns adopted by Target Date Funds such as Vanguard (2019). As shown in Figure 2 (dotted line), a high level of exposure to equity risk (90\%) is maintained until the age of 40. Then, the stock share declines steadily over the remaining working life down to $50 \%$ at retirement (age 65) and is further reduced in the early retirement period to reach $30 \%$ at age $72 .{ }^{9}$ This "Target Date Fund $(T D F)$ rule" happens to be close to the optimal life-cycle risky investment profile in the absence of long-term unemployment risk.

The metric used to perform welfare comparisons is the standard consumption-equivalent (CE) variation. ${ }^{10}$ The CE variation is computed as the percentage increase in annual con-

\footnotetext{
${ }^{9}$ In Vanguard's Target Date Fund "glide path" asset allocation, the portfolio share not invested in (U.S. and international) stocks is invested in (U.S. and international) bonds and short-term Treasury InflationProtected Securities (Vanguard, 2019).

${ }^{10}$ This metric is employed, among others, by Cocco, Gomes and Maenhout (2005), Chai, Horneff, Maurer and Mitchell (2011), Winter, Schlafmann and Rodepeter (2012) and Love (2013).
} 
sumption an investor following a given rule of thumb would need to enjoy the same expected lifetime utility associated with the optimal asset allocation strategy.

In particular, when the agent chooses optimally consumption and the stock portfolio share, we obtain expected lifetime utility $V_{t_{0}}^{*}$ at the beginning of her working life (age 20) as:

$$
V_{t_{0}}^{*}=E_{t_{0}}\left[\sum_{j=0}^{T} \beta^{j}\left(\prod_{k=-1}^{j-1} p_{t_{0}+k}\right) \frac{C_{t_{0}+j}^{* 1-\gamma}}{1-\gamma}\right]
$$

where $C_{t_{0}+j}^{*}$ denotes optimal consumption in period $t_{0}+j$. We convert this measure into consumption units by computing the constant consumption stream $C^{*}$ that yields a discounted expected utility equal to $V_{t_{0}}^{*}$ :

$$
C^{*}=\left[\frac{(1-\gamma) V_{t_{0}}^{*}}{\sum_{j=0}^{T} \beta^{j}\left(\prod_{k=-1}^{j-1} p_{t_{0}+k}\right)}\right]^{\frac{1}{1-\gamma}}
$$

Following the same procedure, when the investor maximizes utility using a rule of thumb for portfolio allocation (either the "age rule" or the "Target Date Fund rule"), we obtain the corresponding expected lifetime utility $V_{t_{0}}^{R}$ and the equivalent constant consumption stream $C^{R}$. Thus, the welfare cost $W_{t_{0}}^{R}$ for an investor at the beginning of her working life can be computed as the percentage loss in equivalent consumption suffered when she adopts an investment rule of thumb instead of the optimal strategy:

$$
W_{t_{0}}^{R}=\frac{V^{* \frac{1}{1-\gamma}}-V^{R \frac{1}{1-\gamma}}}{V^{R \frac{1}{1-\gamma}}}=\frac{C^{*}-C^{R}}{C^{R}}
$$

In practice, we simulate the discounted lifetime utility of 200.000 workers both under the optimal solution and under alternative simple investment rules of thumb, and use the averages across individuals to obtain a measure of the welfare loss according to (10).

Table 2 shows lifetime welfare losses, expressed in annual percentage CE variation, associated with the adoption of suboptimal rules of thumb in asset allocation. As a benchmark for comparison, the first row presents the welfare loss obtained when there is no unemployment risk, ${ }^{11}$ as in the standard life-cycle setup of Cocco, Gomes and Maenhout (2005), and the optimal risky share is that displayed as the grey line in Figure 1. In this environment, both the "age" and the "TDF" rules are relatively close to the optimal profile and the loss is

\footnotetext{
${ }^{11}$ All parameter values are calibrated as shown in Table 1.
} 
rather small (0.55\% and $0.18 \%$, respectively), well in the range of other available results in the literature. When the risk of permanent decreases in earning prospects due to long-term unemployment is introduced in the model, the optimal age profile of the stock share changes substantially (see Figure 2), and the associated welfare losses are much larger, as shown in the second row of Table 2. Adopting the "age rule" in managing portfolios entails a loss equivalent to around $3 \%$ of annual consumption, which increases up to $8.6 \%$ in the case of the "TDF rule".

\section{Table 2: Welfare Losses}

\begin{tabular}{lcc}
\hline Expected Loss $(\%)$ & Age rule (100-age) & TDF \\
\hline No LTUR & 0.55 & 0.18 \\
LTUR & 2.94 & 8.61 \\
\hline
\end{tabular}

The table shows welfare losses, expressed in \% of annual consumption, due to the adoption of suboptimal investment rules ("age rule" or "Target Date Fund rule") instead of the optimal strategy. In the first row, the optimal solution is obtained in the absence of long-term unemployment risk (No LTUR), whereas in the second row the risk of human capital loss following long-term unemployment is added to the model (LTUR).

Such sizable welfare losses derive from the excess exposure to financial risk early in working life, and the under-exposure in retirement, embedded in the investment rules of thumb relative to the optimal strategy. This is particularly apparent in the case of the "TDF rule", which entails a stock share higher than optimal during almost all working life. The high risk of her financial portfolio (with a $90 \%$ stock share over the first two decades of working life) induces the investor to increase savings and wealth accumulation: consumption is therefore substantially lower than optimal over the first half of the working life, determining a sizeable decrease in expected utility that is not compensated by higher than optimal consumption levels over the remaining years of work and during retirement. Such distortion of the consumption and saving profile under the "TDF rule" yields a welfare loss three times larger than that under the "age rule", which entails more limited departures from the optimal intertemporal consumption pattern. 


\section{Conclusions}

When a small risk of prolonged unemployment is considered, the (otherwise standard) model of life-cycle portfolio choice yields an optimal age profile of stock investment remarkably different from the popular, decreasing with age, pattern. In particular, the exposure to equity risk is much lower for young investors and relatively constant during working life and retirement. We show that in this case the welfare loss associated with the adoption of simple investment rules of thumb related to age is substantial, ranging from $3 \%$ to $9 \%$ of annual consumption. This result suggests a new design for pension plans offered by longterm investors, with a relatively constant equity exposure over the life cycle, suitable to effectively hedge the long-run consequences of long unemployment spells. Moreover, the reduced heterogeneity of the optimal risky share profile implies that relatively standard investment strategies may be appropriate for large classes of workers.

On a more general level, our analysis complements other results in the literature pointing to the relevance of extending life-cycle models of asset allocation to capture major features of labor market uncertainty, of which the risk of human capital loss due to long-term unemployment is one important dimension. 


\section{References}

[1] Bagliano F. C., C. Fugazza and G. Nicodano (2019), Life-Cycle Portfolios, Unemployment, and Human Capital Loss, Journal of Macroeconomics, vol. 60: 325-340.

[2] Bremus F. M. and V. Kuzin (2014), Unemployment and Portfolio Choice: Does Persistence Matter?, Journal of Macroeconomics, vol. 40(C): 99-113.

[3] Chai J., W. Horneff, R. Maurer and O.S. Mitchell (2011), Optimal Portfolio Choice over the Life Cycle with Flexible Work, Endogenous Retirement, and Lifetime Payouts, Review of Finance, 15: 875-907.

[4] Chang Y., J. H. Hong and M. Karabarbounis (2018), Labor-Market Uncertainty and Portfolio Choice Puzzles, American Economic Journal: Macroeconomics, 10(2): 222-262.

[5] Cocco J., F. J. Gomes and P. J. Maenhout (2005), Consumption and Portfolio Choice over the Life Cycle, Review of Financial Studies, 18(2): 491-533.

[6] Couch K. A. and D. W. Placzek (2010), Earnings Losses of Displaced Workers Revisited, American Economic Review, 100(1): 572-89.

[7] Edin P. A. and M. Gustavsson (2008), Time Out of Work and Skill Depreciation, Industrial Labor Relations Review, 61(2): 163-180.

[8] Gomes F. J, L.J. Kotlikoff and L.M. Viceira (2008), Optimal Life-Cycle Investing with Flexible Labor Supply: A Welfare Analysis of Life-Cycle Funds, American Economic Review, 98(2): 297-303.

[9] Gomes F. J and A. Michaelides (2005), Optimal Life-Cycle Asset Allocation: Understanding the Empirical Evidence, Journal of Finance, 60(2): 869-904.

[10] Guevenen F., F. Karahan, S. Ozkan and J. Song (2017), Heterogeneous Scarring Effects of Full-Year Nonemployment, American Economic Review, vol. 107(5): 369-373.

[11] Jacobson L., R. LaLonde and D. Sullivan (1993), Earnings Losses of Displaced Workers, American Economic Review, 83(4): 685-709. 
[12] Jacobson L., R. LaLonde and D. Sullivan (2005), Estimating the Returns to Community College Schooling for Displaced Workers, Journal of Econometrics, 125(1-2): 271-304.

[13] Kroft K., F. Lange, M.J., Notowidigdo and L. Katz (2016), Long Term Unemployment and the Great Recession: the Role of Composition, Duration Dependence, and Non Participation, Journal of Labor Economics, 34(S1): S7-S54.

[14] Love D.A. (2013), Optimal Rules of Thumb for Consumptin and Portfolio Choice, Economic Journal, 123(7): 932-961.

[15] OECD (2010), OECD Employment Outlook 2010: Moving beyond the Jobs Crisis, OECD Publishing, Paris.

[16] OECD (2015) Pensions at a Glance 2015: Retirement-Income Systems in OECD and G20 Countries, OECD Publications, Paris.

[17] Schmieder J. F., T. von Wachter, and S. Bender (2016), The Effect of Unemployment Benefits and Nonemployment Durations on Wages, American Economic Review, 106(3): 739-77.

[18] Vanguard (2019), Vanguard's Approach to Target-Date Funds, Vanguard Research paper, March.

[19] Viceira L. M. (2001), Optimal Portfolio Choice for Long-Horizon Investors with Nontradable Labor Income, The Journal of Finance, 56: 433-470.

[20] Winter J.K., K. Schlafmann and R. Rodepeter (2012), Rules of Thumb in Life-Cycle Saving Decisions, Economic Journal, 122(4): 479-501.

\section{Supplementary material}

Supplementary material associated with this article is available in the online Appendix, containing details on the model's solution procedure, on the properties of the optimal policy functions for the portfolio stock share, and robustness checks. 


\title{
Life-Cycle Welfare Losses from Rules-of-Thumb Asset Allocation Supplementary online Appendix
}

\author{
August 2020
}

This Appendix provides additional material to the paper "Life-Cycle Welfare Losses from Rules-of-Thumb Asset Allocation" (F.C. Bagliano, C. Fugazza and G. Nicodano). Section A presents details on the solution of the intertemporal utility maximization problem, Section

B discusses the properties of the optimal policy functions for the portfolio stock share, and Section C presents some robustness checks.

\section{A Solving the life-cycle problem}

The individual intertemporal utility maximization problem presented in Section 2 can be stated in a recursive form, writing the value of the optimization problem at time $t$ as a function of current utility and the value of the problem at time $t+1$. The resulting Bellman equation is (6) in the main text, where the expectation over the worker's employment state at $t+1$ is made explicit, and is reported here for convenience:

$$
\begin{aligned}
V_{t}\left(X_{t}, P_{t}, s_{t}\right)=\max _{C_{t}, \alpha_{t}^{s}} \frac{C_{t}^{1-\gamma}}{1-\gamma}+\beta & {\left[p_{t} \sum_{s_{t+1}=e, u_{1}, u_{2}} \pi\left(s_{t+1} \mid s_{t}\right) \widetilde{E}_{t} V_{t+1}\left(X_{t+1}, P_{t+1}, s_{t+1}\right)\right.} \\
& \left.+\left(1-p_{t}\right) b \frac{\left(X_{t+1} / b\right)^{1-\gamma}}{1-\gamma}\right]
\end{aligned}
$$

where $\widetilde{E_{t}} V_{t+1}$ denotes the expectation operator taken with respect to the stochastic variables $\omega_{t+1}, \varepsilon_{t+1}$, and $\nu_{t+1}^{s}$. The history dependence that we introduce by making unemployment affect subsequent labor income prospects prevents using the standard normalization of the 
problem with respect to the level of $P_{t}$. To highlight how the evolution of the permanent component of labor income depends on previous individual labor market dynamics we write the value function at $t$ in each possible state (dropping for simplicity the term involving the bequest motive) as:

$$
\begin{aligned}
& V_{t}\left(X_{t}, P_{t}, e\right)=u\left(C_{t}\right)+\beta p_{t}\left\{\begin{array}{l}
\left\{\begin{array}{l}
\widetilde{E_{t}} V_{t+1}\left(X_{t+1}, P_{t+1}, e\right) \quad \text { with prob. } \pi_{e, e} \\
\text { with } P_{t+1}=P_{t} e^{\omega_{t+1}} \quad \text { and } \\
X_{t+1}=\left(X_{t}-C_{t}\right) R_{t}^{p}+F_{t+1} P_{t+1} e^{\varepsilon_{t+1}}
\end{array}\right. \\
\left\{\begin{array}{l}
\widetilde{E_{t}} V_{t+1}\left(X_{t+1}, P_{t+1}, u_{1}\right) \quad \text { with prob. } 1-\pi_{e, e} \\
\text { with } P_{t+1}=\left(1-\Psi_{1}\right) P_{t} \quad \text { and } \\
X_{t+1}=\left(X_{t}-C_{t}\right) R_{t}^{p}+\xi_{1} F_{t} P_{t}
\end{array}\right.
\end{array}\right. \\
& V_{t}\left(X_{t}, P_{t}, u_{1}\right)=u\left(C_{t}\right)+\beta p_{t}\left\{\begin{array}{l}
\left\{\begin{array}{l}
\widetilde{E}_{t} V_{t+1}\left(X_{t+1}, P_{t+1}, e\right) \quad \text { with prob. } \pi_{u_{1}, e} \\
\text { with } P_{t+1}=\left(1-\Psi_{1}\right) P_{t-1} e^{\omega_{t+1}}=P_{t} e^{\omega_{t+1}} \quad \text { and } \\
X_{t+1}=\left(X_{t}-C_{t}\right) R_{t}^{p}+F_{t-1} P_{t+1} e^{\varepsilon_{t+1}}
\end{array}\right. \\
\left\{\begin{array}{l}
\widetilde{E}_{t} V_{t+1}\left(X_{t+1}, P_{t+1}, u_{2}\right) \quad \text { with prob. } 1-\pi_{u_{1}, e} \\
\text { with } P_{t+1}=\left(1-\Psi_{2}\right)\left(1-\Psi_{1}\right) P_{t-1}=\left(1-\Psi_{2}\right) P_{t} \text { and } \\
X_{t+1}=\left(X_{t}-C_{t}\right) R_{t}^{p}+\xi_{2} F_{t-2} P_{t-2}
\end{array}\right.
\end{array}\right. \\
& V_{t}\left(X_{t}, P_{t}, u_{2}\right)=u\left(C_{t}\right)+\beta p_{t}\left\{\begin{array}{l}
\left\{\begin{array}{l}
\widetilde{E_{t}} V_{t+1}\left(X_{t+1}, P_{t+1}, e\right) \quad \text { with prob. } \pi_{u_{2}, e} \\
\text { with } P_{t+1}=P_{t} e^{\omega_{t+1}} \quad \text { and } \\
X_{t+1}=\left(X_{t}-C_{t}\right) R_{t}^{p}+F_{t-2} P_{t+1} e^{\varepsilon_{t+1}}
\end{array}\right. \\
\left\{\begin{array}{l}
\widetilde{E_{t}} V_{t+1}\left(X_{t+1}, P_{t+1}, u_{2}\right) \quad \text { with prob. } 1-\pi_{u_{2}, e} \\
\text { with } P_{t+1}=\left(1-\Psi_{2}\right) P_{t} \text { and } \\
X_{t+1}=\left(X_{t}-C_{t}\right) R_{t}^{p}+\xi_{2} F_{t-2} P_{t-2}
\end{array}\right.
\end{array}\right.
\end{aligned}
$$

To solve the problem, in the absence of a closed form solution, we apply standard numerical techniques. The method involves iteration on the value function to find the optimal consumption and portfolio shares given the initial level of assets, permanent income and employment state. Beginning from the last period of life $T$, the problem is solved backwards, by means of the standard grid search method, for every period $t=T-1, T-2, \ldots, t_{0}$ using the Bellman equation (A.1). This yields the policy functions for consumption and the risky 
portfolio share. The latter are shown and discussed in the following section.

\section{B Policy functions for risky portfolio shares}

In this section we compare investors' optimal stock shares in the standard case without unemployment risk and in our alternative scenario with long-run unemployment risk and human capital loss. Figure B.1 plots the optimal stock share as a function of cash on hand for an average level of the permanent labor income component of investors at three different ages: 20 (solid lines) 40 (dashed lines) and 70 (dotted lines). Without unemployment risk (grey lines), standard life-cycle results are obtained. Labor income acts as an implicit riskfree asset and affects the optimal portfolio composition depending on investors' age and wealth. For example, at age 20 the sizable implicit holding of the risk-free asset (through human capital) makes it optimal for less wealthy investors to tilt their portfolio towards the risky financial asset. Indeed, for a wide range of wealth levels, agents optimally choose to be fully invested in stocks. The optimal stock holding decreases with financial wealth because of the relatively lower implicit investment in (risk-free) human capital.

When the model is extended to allow for permanent effects of long-term unemployment spells on future labor income prospects, the resulting policy functions (black lines in Figure B.1) are shifted abruptly leftward for individuals of age 20 and 40. Now unemployment may cause the loss of a substantial portion of future incomes, severely reducing the level of human capital and increasing its risk at all ages. Thus, full investment in stocks is optimal only at extremely low wealth levels; as cash on hand increases, the risky share is considerably lower than in the absence of unemployment risk. Moreover, the remarkably flat shape of the

policy functions over a wide range of wealth levels determines the reduced heterogeneity of asset allocation choices during working life documented in Figure 1 in the main text. Only in the case of retirees (age 70), who do not face unemployment risk anymore, the two policy functions are relatively close. 


\section{Figure B.1: Policy functions}

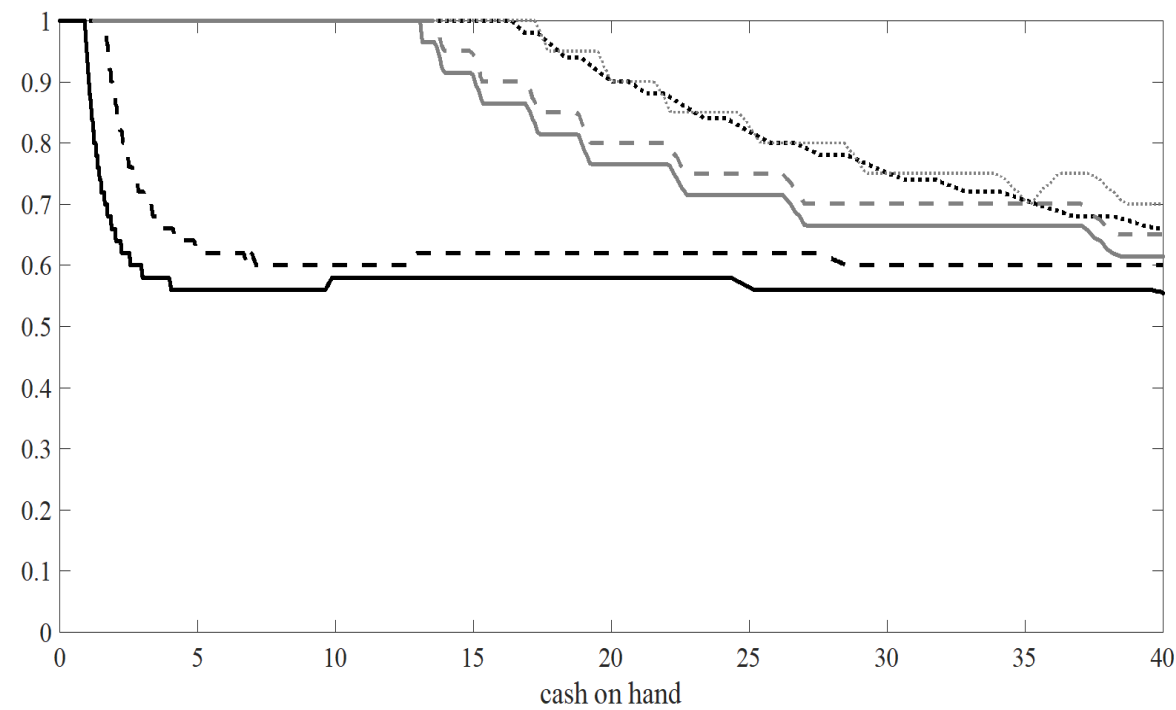

This figure shows the portfolio rules for stocks as a function of cash on hand for an average level of the stochastic permanent labor income component. The policies refer to selected ages: 20 (solid lines), 40 (dashed lines) and 70 (dotted lines). Grey and black lines refer respectively to the cases with no unemployment risk and with unemployment risk and human capital loss. In the latter case, the parameters governing the human capital loss during short-term and long-term unemployment spells are $\Psi_{1}=0$ and $\Psi_{2}=0.25$. Cash on hand is expressed in ten thousands of U.S. dollars.

\section{Robustness}

In this section, we first present life-cycle profiles of stock investment obtained allowing for a positive correlation between stock return and permanent labor income innovations $\left(\rho_{s Y}>0\right)$, as well as long-term unemployment risk. Bagliano, Fugazza and Nicodano (2014) show that a realistically small correlation has large effects on life-cycle choices when it interacts with a higher variance of the permanent component of labor income shocks. One may therefore expect a similar effect in the presence of risk of human capital loss. Empirical estimates of the stock return-labor income correlation differ widely, even for the U.S. economy. Cocco, Gomes and Maenhout (2005) report estimated values not significantly different from zero across various education groups, in line with Heaton and Lucas (2000), whose estimates range 
from -0.07 to 0.14 . However, Campbell, Cocco, Gomes and Maenhout (2001) find higher values, ranging from 0.33 for households with no high school education to 0.52 for college graduates. In the simulations below, we adopt an intermediate positive value of $\rho_{s Y}=0.2$.

Figure C.1 shows optimal portfolio shares of stocks with $\rho_{s Y}=0$ (benchmark case) and $\rho_{s Y}=0.2$. While the shape of life-cycle profiles is relatively unaffected, the average stock share is lower at all ages during working life. In case of positive correlation, labor income is closer to an implicit holding of stocks, reducing the incentive to invest in risky assets at all ages. More specifically, in comparison with the case of no correlation, such investors are relatively more exposed to stock market risk and will prefer to hedge such risk by holding a lower fraction of their financial portfolio in stocks. The stock share remains substantially flat over the whole working life, displaying limited variability around a level of about $50 \%$. At the retirement age of 65, human capital becomes riskless since pension income is certain and therefore uncorrelated with stock return innovations. Thus investors rebalance their portfolio towards stocks; during retirement, the level and time profile of the stock share are very close to the case of no correlation.

Figure C.1: Life-cycle stock share profiles with unemployment and human capital loss: positive correlation between labor income and stock returns

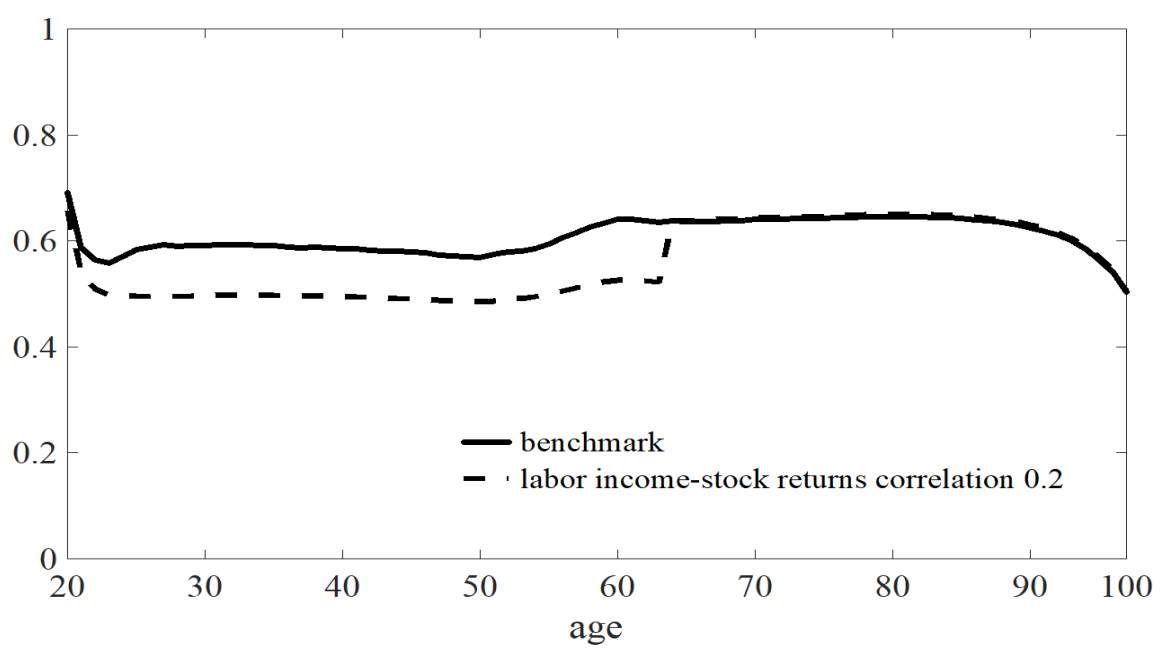

This figure displays the average simulated stock investment life-cycle profiles for individuals of age 20 to 100. Positive correlation between labor income shocks and innovation to stock returns: $\rho_{s Y}=0.2$. Human capital loss: $\Psi_{1}=0$ and $\Psi_{2}=0.25$. 
Secondly, we implement a change in preferences that allows for intertemporal correlation aversion (Bommier, 2007). With a power utility function, the worker is indifferent to positive or negative intertemporal correlation of consumption (shocks). With Epstein-Zin preferences, the worker is averse to positive correlation when the coefficient of relative risk aversion is greater than the inverse of the elasticity of intertemporal substitution $(E I S)$. Adopting a recursive (Epstein-Zin) formulation for preferences and keeping the risk aversion parameter constant at our benchmark level $(\gamma=5)$, we simulate the model with positive $(E I S=0.5)$ and negative $(E I S=0.1)$ correlation aversion, comparing the results with our baseline case of indifference (i.e., power utility, $E I S=0.2$ ). Figure C.2 shows that aversion to positive correlation has a negligible effect during working years, while it causes less risk taking during the retirement period, especially as death approaches. This finding is consistent with the known property that higher mortality risk magnifies the effects of intertemporal correlation aversion (Bommier, 2013).

Overall, the preceding experiments support the robustness of the flattening of the lifecycle profile to changes in hedging opportunities in the stock market and to different preference specifications.

Figure C.2: Life-cycle stock share profiles with unemployment and human capital loss: recursive preferences

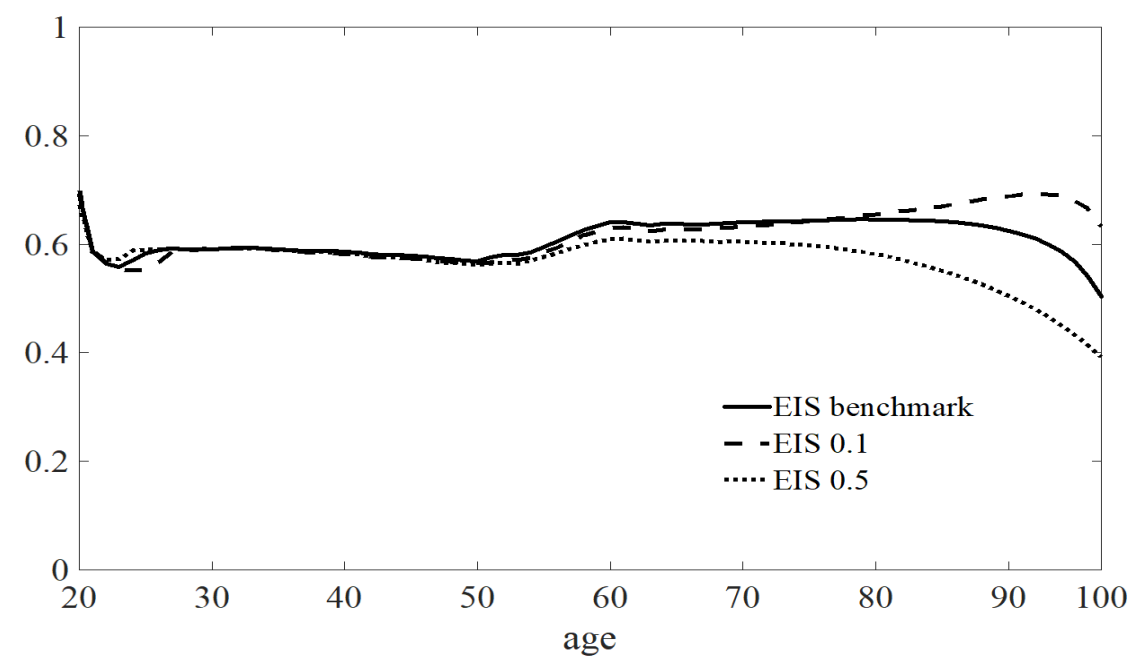

This figure displays the average simulated stock investment life-cycle profiles for individuals of age 20 to 100 . Preferences over consumption are recursive, represented by an Epstein Zin utility function. The elasticity of intertemporal substitution parameter (set at 0.2 in the benchmark case) varies from 0.1 to 0.5. 


\section{References}

[1] Bagliano F. C., C. Fugazza and G. Nicodano (2014), Optimal Life-Cycle Portfolios for Heterogeneous Workers, Review of Finance, 18(6): 2283-2323.

[2] Bommier A. (2007), Risk Aversion, Intertemporal Elasticity of Substitution and Correlation Aversion, Economics Bulletin, 4(29): 1-8.

[3] Bommier A. (2013), Life-Cycle Preferences Revisited, Journal of the European Economic Association, 11(6): 1290-1319.

[4] Campbell J.Y., J. Cocco, F.J. Gomes and P.J. Maenhout (2001), Investing Retirement Wealth: a Life-Cycle Model, in Campbell J.Y. and M. Feldstein (eds.), Risk Aspects of Investment-Based Social Security Reform, University of Chicago Press.

[5] Cocco J., F. J. Gomes and P. J. Maenhout (2005), Consumption and Portfolio Choice over the Life Cycle, Review of Financial Studies, 18(2): 491-533.

[6] Heaton J. and D. Lucas (2000), Portfolio Choice and Asset Prices: The Importance of Entrepreneurial Risk, Journal of Finance, 55(3): 1163-1198. 


\section{DEPARTMENT OF ECONOMICS AND STATISTICS \\ UNIVERSITY OF TORINO}

Corso Unione Sovietica 218 bis - 10134 Torino (ITALY)

Web page: http://esomas.econ.unito.it/ 